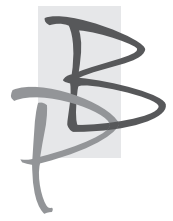

Anna Janicka*

Uniwersytet w Białymstoku

https://orcid.org/0000-0003-0289-3706

\title{
Międzynarodowa Konferencja Naukowa „Emigracja niepodległościowa ukraińska i polska w wieku XX. Tradycje - osobowości - idee - retoryki", Kijów, 23-25 maja 2018. Sprawozdanie
}

W dniach 23 - 25 maja 2018 roku obradowała w Kijowie Międzynarodowa Konferencja Naukowa „Emigracja niepodległościowa ukraińska i polska w wieku XX. Tradycje - osobowości - idee - retoryka”. Było to ogromne polsko-ukraińskie przedsięwzięcie, zorganizowane przede wszystkim siłami Katedry Polonistyki Narodowego Uniwersytetu im. T. Szewczenki w Kijowie oraz Zakładu Filologicznych Badań Interdyscyplinarnych z Wydziału Filologicznego Uniwersytetu w Białymstoku. Obie jednostki od dawna specjalizują się w badaniach emigracji ukraińskiej i polskiej.

Wysiłek przygotowania Konferencji wsparły organizacyjnie i finansowo liczne polskie i ukraińskie instytucje, w tym: Ambasada RP w Kijowie, Książnica Podlaska im. Łukasza Górnickiego w Białymstoku, Przedstawicielstwo PAN w Kijowie, Instytut Literatury im. T. Szewczenki NAN Ukrainy i Międzynarodowa Szkoła Ukrainistyki NAN Ukrainy.

Wysiłkom Komitetu Organizacyjnego Konferencji przewodniczyli: prof. Rościsław Radyszewski (Katedra Polonistyki), dr hab. Anna Janicka, prof. UwB (ZFBI, UwB), dr hab. Violetta Wejs-Milewska, prof. UwB (ZFBI, UwB), prof. Lucjan Suchanek (Przewodniczący Komisji Emigrantologii Słowian Między-

\footnotetext{
* Anna Janicka - dr hab., prof. UwB; pracuje w Zakładzie Filologicznych Badań Interdyscyplinarnych Uniwersytetu w Białymstoku. Autorka książek: Sprawa Zapolskiej. Skandale i polemiki (Białystok 2013, wyd. 2: Białystok 2015); Tradycja i zmiana. Literackie modele dziewiętnastowieczności: pozytywizm i ,obrzeża” (Białystok 2015).
} 
narodowego Komitetu Slawistycznego, PAU), dr hab. Mariya Bracka (Katedra Polonistyki) ${ }^{1}$. Komitetowi Naukowemu sesji przewodniczyli: dr Nina TaylorTerlecka (Oxford, Wielka Brytania) i prof. Leonid Huberski (Narodowy Uniwersytet im. T. Szewczenki)2. Była to wielka, właściwie 5-dniowa impreza nauko-

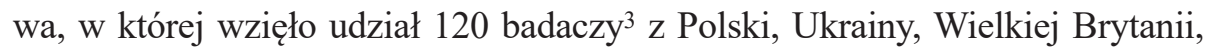
Tajwanu, Włoch.

Należy podkreślić, iż szczególnie udana była część naukowa Konferencji odbywająca się I i II dnia obrad. Została perfekcyjnie przygotowana przez ukraińsko-polski zespół.

Obrady rozpoczęto $23 \mathrm{~V}$ w Auli Instytutu Filologii Narodowego Uniwersytetu im. T. Szewczenki w Kijowie (al. T. Szewczenki 14). Jest to centralny - obok Akademii Nauk - ośrodek badań filologicznych na Ukrainie. Inaugurację poprowadził prof. Rościsław Radyszewski, kierujący kijowską polonistyką, udzielając głosu: JM Rektorowi Uniwersytetu im. T. Szewczenki prof. Leonidowi Huberskiemu, po którym przemawiali prof. Anna Janicka (UwB), prof. Violetta Wejs-Milewska $(\mathrm{UwB})$ i zastępująca nieobecnego Ambasadora RP Jana Piekło Radca Ambasady Pani Emilia Jasiuk - kierownik Referatu ds. Współpracy Naukowo-Oświatowej ${ }^{4}$ Głos zabrali także: prof. Hryhorij Semeniuk (Dyr. Instytutu Filologii) oraz Jolanta Gadek (Dyr. Książnicy Podlaskiej).

Obrady plenarne otworzyły istotne wystąpienia: prof. Lucjana Suchanka (PAU), Emigracja i emigrantologia; dr Niny Taylor-Terleckiej (Oxford), Ty-

1 W jego skład weszli jeszcze: prof. Ołeksandr Astafjew (Kijów), dr Łukasz Zabielski (Książnica Podlaska), dyr. Hałyna Soroka (Muzeum Literatury w Kijowie), mgr Urszula Trochimowicz - Sekretarz (UwB), mgr Irena Szewczenko - Sekretarz (UwB), mgr Ołeksandra Iwanczuk - Sekretarz (Kijów).

2 W skład Komitetu Naukowego wchodzili ponadto: prof. Mykoła Żułyński (NAN), prof. Petro Beck (Uniwersytet Kijowski), prof. Hryhorij Semeniuk (Uniwersytet Kijowski), prof. Ludmiła Hrycyk (Uniwersytet Kijowski), prof. Jewhen Nachlik (NAN), prof. Henryk Sobczak (PAN), Dmytro Pawłyczko (Kijów), dyr. Jolanta Gadek (Książnica Podlaska), dr hab. Jerzy Sikora (UKSW, Warszawa).

3 Liczba referentów rzeczywiście obecnych na sesji była przynajmniej o 1/3 mniejsza. Nie dopisali szczególnie referencji z prowincjonalnych ośrodków ukraińskich, kijowscy prawnicy, historycy.

4 Należy wyrazić żal, iż Ambasador RP odwołał swą obecność w ostatniej chwili, jak zwykle z „ważnych przyczyn”, co miało ważkie konsekwencje: spore opóźnienie inauguracji. $\mathrm{Z}$ sytuacji tej znakomicie wybrnęła radca Emilia Jasiuk. 


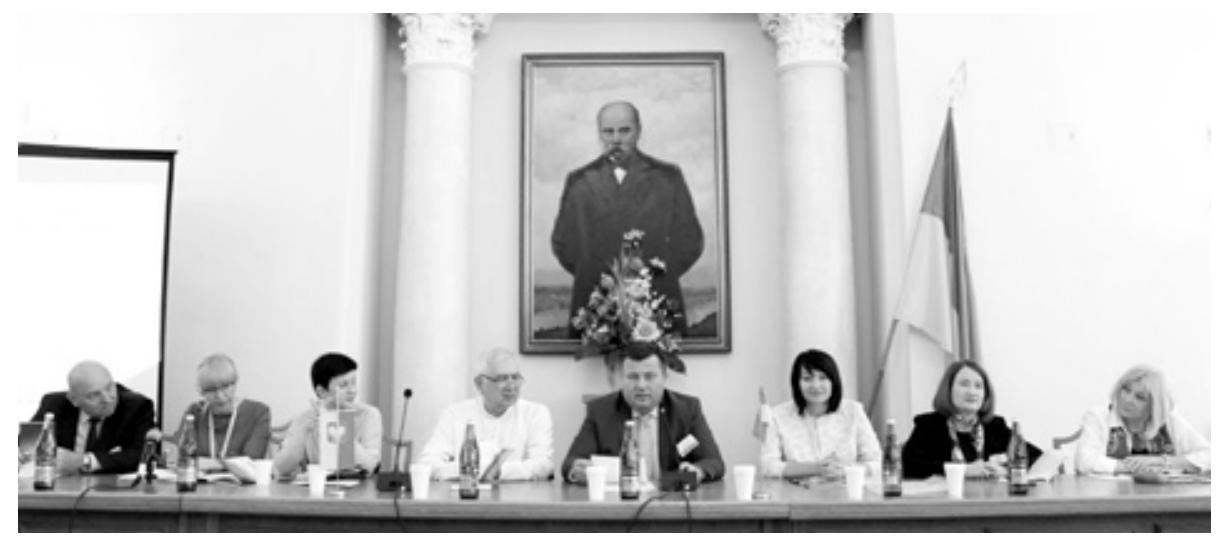

Inauguracja. Od lewej siedzą: prof. W. Sobczak (PAN, Kijów), doc. M. Bracka (Kijów), prof. A. Janicka (UwB), prof. R. Radyszewski (Kijów), prof. L. Huberski (Kijów), nn, radca E. Jasiuk, prof. V. Wejs-Milewska (UwB)

mon Terlecki - profil emigranta; dra Pawła Kowala (PAN) ${ }^{5}$, List ks. Majewskiego jako poczatek idei/doktryny Giedroycia; prof. Iwana Dziuby (NAN), Znany i nieznany Jerzy Giedrojć, prof. Mykoły Żułyńskiego (NAN), „, Kim jestem, dlaczego jestem pośród nich...” Legenda Nataleny Korolewy i prof. Rościsława Radyszewskiego (Katedra Polonistyki), Rozważania jubileuszowe o Juriju Kosaczu. Po przerwie obrady kontynuowane były w czterech sekcjach:

Sekcja I: Wymiary emigracyjnego doświadczenia (przew.: prof. Lucjan Suchanek i prof. Mykoła Zymomrya, prof. Walentyna Sobol i prof. Jarosław Fazan).

Sekcja II: Tożsamość emigranta (przew.: prof. Joel Janicki i prof. Nadija Kołoszuk, prof. Marek Stanisz i prof. Mariya Bracka).

Sekcja III: Joseph Conrad, Jurij Kosacz, Czestaw Miłosz, Wołodymyr Wynnyczenko (przew.: prof. Anna Janicka i prof. Wiktor Humeniuk, prof. Anna Stepanowa i dr Michał Siedlecki).

Sekcja IV: O języku i przektadzie (przew.: prof. Artur Bracki i prof. Anatolij Tkaczenko, dr Joanna Krauze-Karpińska i prof. Witalij Misijenko).

5 Badacz ograniczył swój pobyt na Konferencji do przybycia, odczytania referatu i opuszczenia Konferencji bez udziału w dyskusji. 


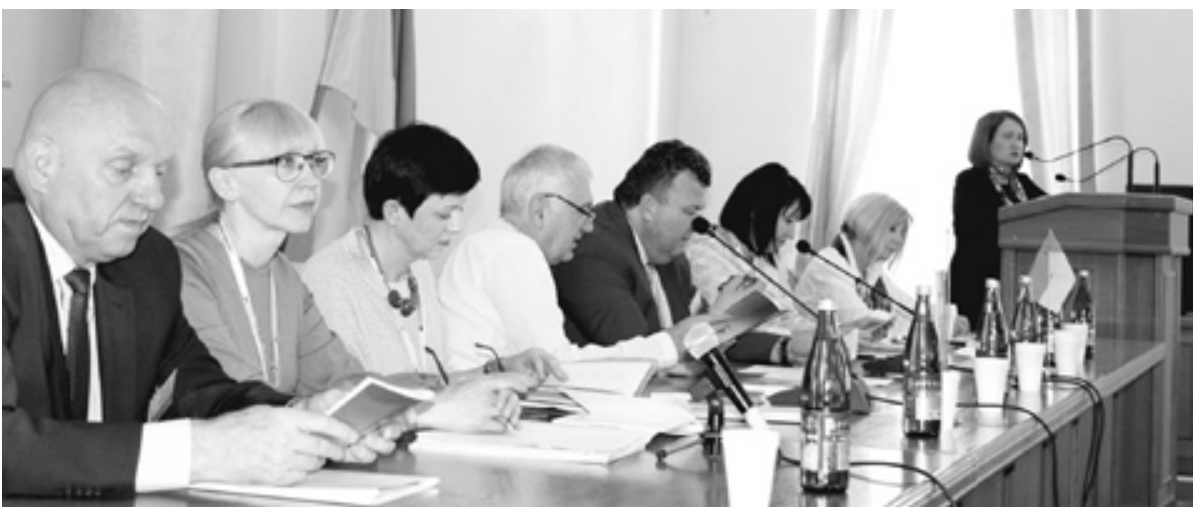

Inauguracja. Od lewej siedzą: prof. W. Sobczak (PAN, Kijów), doc. M. Bracka (Kijów), prof. A. Janicka (UwB), prof. R. Radyszewski (Kijów), prof. L. Huberski (Kijów), nn, radca E. Jasiuk, prof. V. Wejs-Milewska (UwB)

Drugiego i trzeciego dnia Konferencji (24-25 V) obradowano już tylko w sekcjach:

Sekcja I: Szkoła praska (przew.: prof. Violetta Wróblewska, prof. Hryhorij Kłoczek, prof. Hanna Ratuszna, prof. Ludmiła Hrycyk, prof. Barbara Gierszewska, prof. Jewhen Nachlik).

Sekcja II: Wymiary niepodległości, wymiary emigracji (przew.: prof. Violetta Wejs-Milewska, prof. Wołodymyr Pohrebennyk, prof. Agnieszka Czajkowska, prof. Oksana Kornijenko, prof. Jarosław Ławski, prof. Ludmiła Romaszczenko).

Sekcja III: Kwestie polityczne, publicystyka, oświata (przew.: prof. Magdalena Rabizo-Birek, prof. Roman Pichmaniec, prof. Zygmunt Woźniczka, prof. Wołodymyr Jerszow, prof. Iwan Meheła, dr Wojciech Maryjka).

Sekcja IV: Sztuka/teatr/folklor (przew.: prof. Walentyna Siłantjewa, dr hab. Katarzyna Fazan, prof. Ołena Bondarewa, dr Paweł Wojciechowski, dr Łarysa Wachnina, prof. Artur Bracki).

Sekcja V: Literatura - historia - polityka (przew.: prof. Wira Prosałowa, dr Tadeusz Karabowicz, prof. Olga Charłan, dr Iwan Matkowski, prof. Mykoła Tkaczuk).

Sekcja VI: Emigracja i problemy literaturoznawstwa (przew.: prof. Magdalena Rabizo-Birek, prof. Tetiana Bowsuniwska, prof. Hanna Ratuszna, prof. Ołena Jeremenko, prof. Ołeksandr Astafjew i prof. Wołodymyr Pohrebennyk).

Sekcja VII: Kwestie historycznoliterackie (komunikaty) (przew.: prof. Jurij Kowaliw, prof. Wołodymyr Litwynow). 
Sekcja VIII: Historyczna (obrady na Wydziale Historycznym w Czerwonym Gmachu) (przew.: prof. Wasyl Ulianowski, prof. Wołodymyr Serhijczuk).

Sekcja IX: Prawnicza (obrady jak wyżej) (przew.: prof. Wołodymyr Bewzenko i prof. Jarosław Dobkowski) ${ }^{6}$.

W sesji wzięli udział przedstawiciele kilkunastu ośrodków ukraińskich i 18 polskich (UwB, PAU, PAN, UMK, UJ, UW, UR, UWM, AJD, UŚ, AST, Ateneum. Szkoła Wyższa, UMCS, Książnica Podlaska (Dział Naukowy), KUL, UTH, PWSW Przemyśl). Nie sposób wymienić wszystkich ciekawych wystąpień. Przywołajmy kilka wybranych:

- Dr hab. Marek Stanisz, prof. UR, Szewczenko na eksport;

- Dr hab. Jarosław Fazan, prof. UJ, Doświadczenie mentalnego powrotu do ojczyzny jako wymiar tożsamości emigranta;

- Doc. dr Marta Chorob (Uniwersytet Przykarpacki), Z prozy egzystencjalnej W. Domontowycza;

- Yauling Hsieh, prof. Soochov University (Tajwan), In Search of an Identity Through Education in "The Girl Friends" and ,Orphan of Asia”;

- Joel Janicki, prof. Soochov University (Tajwan), Coercion and Coerciveness in the Politics of Cold-War Ukraine and Taiwan;

- Prof. Wołodymyr Jerszow (Żytomierz), Pogranicze ukraińsko-polskie na tamach londyńskiego „Pamiętnika Kijowskiego” (1959-1980);

- Prof. Ołena Bondarewa (Uniwersytet im. B. Hrinczenki, Kijów), Archetyp Wigilii i Wielkanocy $w$ dramacie diaspory ukrainskiej;

- Dr Joanna Krauze-Karpińska (IBL PAN), Emigracyjni badacze polskiej literatury dawnej;

- Prof. Jarosław Ławski (Katedra Badań Filologicznych „Wschód - Zachód”, UwB), ,Ruskie”;

- Prof. Ivan Zymomrya (Drohobycz), Świat emigracji i realia ukraińskie w twórczości Emmy Andijewskiej;

- Prof. Zygmunt Woźniczka (UŚ, Katowice), Władze Rzeczypospolitej na emigracji i w kraju w czasie wojny i po jej zakończeniu wobec Ukrainy zmiany czy kontynuacja?;

6 Pomysł dołączania do sesji literaturoznawczej sekcji prawniczej i historycznej należy uznać za chybiony. Tym bardziej, że historycy i prawnicy obradowali w innym gmachu (nie było kontaktów towarzyskich ani możliwości sprawdzenia, jak odbywają się te obrady, przy jakiej frekwencji referentów). 
- Prof. Jewhen Nachlik (NAN, Lwów, Kijów), Poetyka obrazowości Jewhena Małaniuka;

- Prof. Walentyna Sobol (UW), Dzienniki Aleksandra Koszyca z archiwów Winnipegu;

- Dr hab. Violetta Wejs-Milewska, prof. UwB, Polska emigracja niepodległościowa - idee i (a) doświadczenie;

- Prof. Ludmiła Jerszowa (Kijów, Żytomierz), Problemy ex-terytorialnego patriotyzmu w ego-dokumentach emigrantów ukrainskich XX wieku;

- Prof. Magdalena Rabizo-Birek (UR, Rzeszów), Ukraińscy emigranci w utworach literackich i publicystyce Włodzimierza Odojewskiego;

- Mgr Urszula Trochimowicz (UwB), Ekstremum sytuacji granicznej Czapski o relacjach wschodnich (,, Tumult $i$ widma”);

- Prof. Oksana Slipuszko (Uniwersytet im. T. Szewczenki), Ukraińskie idee polityczne ,, szkoty praskiej”.

Trzeci dzień Konferencji miał odmienny charakter. Zaplanowano na ten czas „Okrągły stół poświęcony 170. rocznicy urodzin Wilhelma Kotarbińskiego", wybitnego polskiego malarza, tworzącego w Kijowie, a następnie „promocję wydań” tomów Katedry Polonistyki oraz Wydziału Filologicznego UwB. Obie imprezy zaplanowane zostały w Narodowym Muzeum Literatury Ukrainy (ul. Chmielnickiego 11), gdzie uczestnicy sesji przybyli po zwiedzaniu Kijowa z przewodnikiem. Trzeba uczciwie powiedzieć, że ukraińskim organizatorom nie starczyło już inwencji na przygotowanie obu imprez. „Okrągły stół” okazał się swobodną gawędą kilku osób7 , zaś prezentacja książek ograniczyła się do pokazania kilku tomów ukraińskich. Sala, w której się to działo, nie spełniała standardów sali konferencyjnej. Nie odbyły się zapowiadane: „zwiedzanie miejsc związanych z W. Kotarbińskim i A. Gorodeckim”, „wystawa prac W. Kotarbińskiego”, „wystawa utworów ukraińskich pisarzy emigrantów" w Muzeum Literatury. Imprezy te zostały włączone do Progra$m u$ na prośbę ukraińskiej strony i dofinansowane przez Ambasadę RP.

Za bardzo udane można natomiast uznać koncert i kolację $23 \mathrm{~V}$ w Międzynarodowym Centrum Kongresowym „Dom Ukraiński” (ul. Chreszczatyk

7 Niestety, nie obyło się bez niemiłych polskim słuchaczom głosów apologetyzujących S. Banderę. Polscy uczeni byli też nieprzyjemnie zaskoczeni formą tych części programu: skrótową, nonszalancką, inną od zapowiedzianej w Programie. 


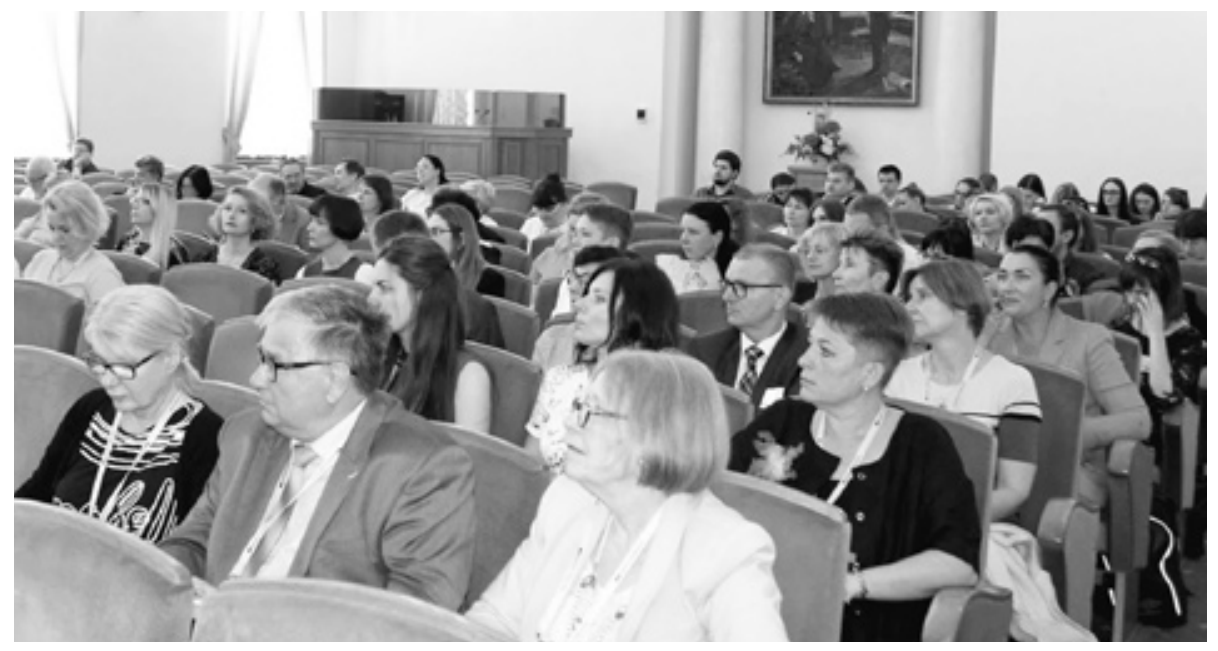

Pierwszy dzień obrad sesji

2). W czasie koncertu ukraińscy wykonawcy śpiewali piosenki do słów prof. Rościsława Radyszewskiego, który jest także poetą, tekściarzem ${ }^{8}$, obchodzącym w ten sposób swoje 70. urodziny. Kolacja odbyła się w ogromnym foyer Centrum Kongresowego. W czasie fety usłyszeliśmy popularne ukraińskie i polskie piosenki, śpiewane Jubilatowi przez kijowskich przyjaciół.

Wysoko ocenić należy poziom naukowy dwu pierwszych dni Konferencji ${ }^{9}$. Zarówno wystąpienia, jak i dyskusje miały stricte naukowy charakter. Odbywały się zaś w atmosferze spokojnego dialogu - dla obu stron wystąpienia polskich i ukraińskich badaczy najczęściej okazywały się odkrywaniem postaci i zjawisk zupełnie nieznanych.

Organizacja tak ogromnej imprezy o zakroju kongresowym byłaby niemożliwa bez zaangażowania osób kierujących imprezą: prof. Rościsława Radyszewskiego, prof. Anny Janickiej, prof. Maryi Brackiej, prof. Lucjana Suchanka, prof. Violetty Wejs-Milewskiej, a także znakomitych osób i instytucji

8 Zob. R. Radiševs'kij, Duša ozvalasâ pisnâmi: (druga kopa pìsen'), Kiiv 2018.

9 W wielu krajach Europy Wschodniej pokutuje zwyczaj dopisywania do Programu sesji osób, które i tak nie wezmą w niej udziału. Ta zła przysługa jest trudna do wykorzenienia. Nie udało się tego zjawiska uniknąć i tym razem (choć w ograniczonym zakresie ono wystąpiło). 
pełniących rolę mecenasa. Tym razem podjęli się jej: niezastąpiona Pani radca Emilia Jasiuk z Ambasady RP ${ }^{10}$, prof. Henryk Sobczak (Przedstawicielstwo PAN na Ukrainie) oraz dyr. Jolanta Gadek (Książnica Podlaska im. Łukasza Górnickiego). W prace przygotowawcze zaangażowani byli także prof. Jarosław Ławski (UwB) i dr Łukasz Zabielski (Książnica Podlaska).

Ogromna robotę w Kijowie i Białymstoku nad przygotowaniem sesji wykonali Sekretarze Konferencji: Ołeksandra Iwanczyk (Kijów), mgr Irena Szewczenko (UwB), mgr Urszula Trochimowicz (UwB), a także dr Barbara Honczarenko (Kijów), dr Michał Siedlecki (Książnica Podlaska) i dr Aleksander Janiszewski (Kijów). Wszystkim tym osobom należą się serdeczne podziękowania!11 Konferencja była okazją do licznych spotkań towarzyskich. Wypada żałować, iż nie wyraził nią bezpośredniego zainteresowania JE Ambasador RP w Kijowie.

Znakomicie funkcję gospodarza pełniła Pani radca Emilia Jasiuk, osoba kluczowa dla przedsięwzięcia. 26 maja zaprosiła ona jeszcze prof. Violettę Wejs-Milewską i prof. Annę Janicką na wykłady w Bibliotece Polskiej im. A. Mickiewicza w Kijowie (ul. I. Franki 16/2), w których uczestniczył m.in. dyrektor wydawnictwa „Znanija”, dr Wołodymyr Rozumnyi, pięknie publikującego przekłady polskiej literatury.

Jak się wydaje, Konferencja spełniła przede wszystkim swój cel towarzyski (poznało się dzięki niej wielu Ukraińców i Polaków, wielu polskich badaczy było po raz pierwszy w Kijowie), lecz też naukowy. Jej plonem będą dwie publikacje - polska i ukraińska. Ta druga już się ukazała - to XXXV tom „Kijowskich Studiów Polonistycznych" z serii prowadzonej przez prof. Rościsława Radyszewskiego (Kijów 2019) ${ }^{12}$. Monografia polska pozostaje w fazie przygotowawczej.

Wypada wyrazić nadzieję, iż zebrane doświadczenia pozwolą uniknąć błędów i tego typu ukraińsko-polskie spotkania będą kontynuowane.

10 Wkrótce po mianowaniu nowego Ambasadora RP, niestety, opuściła Kijów.

11 Należy docenić prace zespołu, który przygotował dwujęzyczny Program (red. M. Bracka, I. Szewczenko, U. Trochimowicz, ISBN 978-83-63470-92-0, Białystok 2018).

12 „Kijowskie Studia Polonistyczne”, T. XXXV, red. K. Strohanova, L. Doroszko, O. Tkaczuk, Kiiv 2019, ss. 511. 